\title{
Analysis of Existing Equations for Calculating the Settling Velocity
}

\author{
M. Shiva Shankar ${ }^{1}$, Manish Pandey ${ }^{1, *}$ and Anoop Kumar Shukla ${ }^{2, *(D)}$ \\ 1 Water Resources and Environment Division, Department of Civil Engineering, National Institute of \\ Technology, Warangal 506004, India; malishivashankar9@gmail.com \\ 2 Manipal School of Architecture and Planning, Manipal Academy of Higher Education, Udupi 576104, India \\ * Correspondence: manishpandey3aug@gmail.com (M.P.); anoopgeomatics@gmail.com (A.K.S.)
}

Citation: Shankar, M.S.; Pandey, M.; Shukla, A.K. Analysis of Existing Equations for Calculating the Settling Velocity. Water 2021, 13, 1987.

https://doi.org/10.3390/w13141987

Academic Editors: Amit Kumar and Zhiguo Yu

Received: 8 June 2021

Accepted: 17 July 2021

Published: 20 July 2021

Publisher's Note: MDPI stays neutral with regard to jurisdictional claims in published maps and institutional affiliations.

Copyright: (c) 2021 by the authors. Licensee MDPI, Basel, Switzerland. This article is an open access article distributed under the terms and conditions of the Creative Commons Attribution (CC BY) license (https:// creativecommons.org/licenses/by/ $4.0 /)$.

\begin{abstract}
The settling velocity of sediment is one of the essential parameters in studying freshwater reservoirs and transporting sediment in flowing water, mainly when the suspension is the dominant process. Hence, their quantitative measurements are crucial. An error during the prediction of the settling velocity may be increased by a factor of three or more in the estimation of the suspended load transport in the flowing water. Despite its significance, obtaining its real value in situ is practically impossible, and it is usually derived via laboratory tests or anticipated by empirical formulas. Numerous equations are available to calculate the settling velocity of the particle. However, it is exceedingly difficult to choose the best method when giving a specific solution for the same problem. Hence, a review of the existing equations is required. In this study, extensive data on settling velocity is collected from the literature, and previously proposed equations are analysed using graphical and statistical analysis.
\end{abstract}

Keywords: terminal fall velocity; water quality; shape factor; sediment

\section{Introduction}

Terminal fall velocity of the particle is defined as a constant velocity achieved by a particle freely falling through a low, dense fluid, and this is also called settling velocity. It occurs when drag force $\left(F_{d}\right)$ on a sediment particle and the buoyancy is equal to the downward force of gravity $\left(F_{G}\right)$, and the particle stops accelerating and continues falling at a constant velocity that is known as terminal velocity. The particle acceleration ceases by the combined action of fluid drag and submerged weight of the particle. In other words, the fall velocity of a particle is measured by equating the gravity and drag forces. To know the insight of sediment transport processes in combined sewers and rivers, fall velocity is an essential factor in accurate prediction. The sediment fall velocity depends on the fluid's density and viscosity and the particle's density, size, and shape [1-8]. Researchers have established many empirical and semi-empirical equations to answer problems such as the fall velocity of particle and sediment transport processes, started by Stokes in 1851. Initially, the settling velocity of sediment equations was developed by assuming the particles to be spheres [1,9-12]. Practically, sediment particles' shapes depart from the sphere, which causes a reduction in settling velocity compared with the sphere [13-16]. As a result of these practical implications, many equations have been developed to compute the settling velocity of natural sediments with an assumption of sphere with the nominal diameter (i.e., the diameter of a sphere with the same volume as a particle of natural sediment) [2-8]. Previous studies on concentrated suspensions of cohesive sediment flocs $[5,16]$ and non-cohesive sediment particles [5,8] revealed that the three unique mechanisms associated to the existence of the cohesive floc/non-cohesive particle concentration cause the impeded settling characteristics, viz.: (i) generating a return flow and forming a wake; (ii) an increase in the viscosity of the mixture; and (iii) influence of buoyancy. In this regard, the settling properties of monodisperse non-cohesive or flocculated suspensions have been widely studied and the approach proposed 
by Rijn [5], or some related variation, are used in the majority of impeded settling models in cohesive streams. When it comes to cohesive sediments, precise estimation of the settling fall velocity characteristics of cohesive flocs is a key factor and it is important to determine their interactions, transport, and fate within the cohesive stream beds. Characterises of cohesive flocs are critical for maintaining and managing navigation channels, ports, and harbours, as well as determining the consequences of increased turbidity on water quality and aquatic habitats in cohesive bed streams. The size and density of the flocs in cohesive sediments are both affected by the flow field and each other. There are several processes that can influence the settling velocity of individual particles in a concentrated suspension. In this paper, we categorized the equations based on the particle size ranges with and without particle shape factors. Most of the previous studies on settling velocity of natural sediment particles that have been carried out explicitly did not take the particle shape factor and roundness into account, which was assumed as 0.7 and 3.5, respectively [7,9-14]. More recently, Jimenez and Madsen [8], Wu and Wang [15], and Camenen [16] developed some empirical equations, which include the particle size, shape, and roundness directly. These equations may perform differently because of the different methods and data sets employed in their calibration.

However, it is exceedingly difficult to choose the best method among them when numerous existing methods give a distinct solution for the same problem. Hence, a review of the existing equations is required. Predominantly, decades ago, many empirical equations were developed based on a limited number of field and experimental data. Several new or retrieved old datasets from different locations may be used to improve the consistency and accuracy of these equations. With this aim, in the present study, several existing equations for settling the velocity of particles were tested for reliability and accuracy using data collected from the literature.

\section{Existing Equations for Settling Velocity of Sediments}

Numerous field and laboratory investigations have been conducted to calculate the Settling velocity of sediment particles. To compute the variation of settling velocity for different particle sizes and shapes, many previous researchers developed the formula for fall velocity of the natural particle. In the present study, fourteen (eleven without shape factor, $S_{f}$; and three with shape factor, $S_{f}$ ) previously developed empirical equations $[2,3,5-7,9,10,12,15,16]$ are selected for verifying their accuracy and these equations are listed below. A shape factor is defined as an irregularity in the shape of a particle from the sphere. Here, csf (Corey shape factor) is used to measure irregularity, which is formulated as $\mathrm{csf}=\mathrm{c} /(a b)^{0.5}$, where $\mathrm{a}, \mathrm{b}$, and c are the lengths of the longest axis, the intermediate axis, and the shortest axis, respectively.

First, Stokes [17] derived an expression for terminal fall velocity $\left(\omega_{s}\right)$ by equating the drag and submerged weight of the particle as:

$$
\omega_{s}^{2}=\frac{4}{3 C_{d}} \frac{\left(\rho_{s}-\rho\right)}{\rho} g d
$$

where $\rho_{s}=$ sediment density, $\rho=$ water density, $g=$ gravitational acceleration, $C_{d}=$ drag coefficient, and $d=$ nominal diameter (diameter of the sphere that has the same volume as the particle). Stokes [17] found that $C_{d}$ for low particle Reynolds number $\left(R_{e}<1\right)$ is inversely proportional to $R_{e}$. $C_{d}=\frac{24}{R_{e}}$ and $R_{e}=\frac{\omega_{s} d}{\vartheta}$. He modified Equation (1) as:

$$
\omega_{s}=\frac{1}{18} \frac{g(S-1) d^{2}}{\vartheta}
$$

where $S$ is the relative density of sediment and $\vartheta=$ kinematic viscosity of water.

On the other hand, for a higher Reynold number $\left(R_{e}>10^{5}\right)$, the $C_{d}$ is found to be a constant [17].

Ruby [2] was the first researcher who proposed an expression to cover all types of settling regimes, written as:

$$
\omega_{s}=F[d g(S-1)]^{0.5}
$$


where $F$ is the dimensionless constant that depends on particle diameter $(d)$ and $F \approx 0.8$ for particles $\geq 1 \mathrm{~mm}$. For particles $<1 \mathrm{~mm}, F$ is determined as:

$$
F=\left[\frac{2}{3}+\frac{36 \vartheta^{2}}{g d^{3}(S-1)}\right]^{0.5}-\left[\frac{36 \vartheta^{2}}{g d^{3}(S-1)}\right]^{0.5}
$$

Zhang [9] proposed a simple equation with different diameter range, viz., clay-sand, sand, and gravel up to $16 \mathrm{~mm}$.

$$
\omega_{s}=\sqrt{\left[\left(13.95 \frac{\vartheta}{d}\right)^{2}+1.09(S-1) g d\right]}-13.95 \frac{\vartheta}{d}
$$

Zanke [3], Soulsby [12], and Julien [10] developed similar equations to compute the settling velocity and gave the relation for the particle Reynolds number, which is rewritten in the following notation:

$$
\begin{gathered}
\omega_{s}=\frac{4 A \vartheta}{d}\left[\left(1+B \frac{(s-1) g d^{3}}{\vartheta^{2}}\right)^{0.5}-1\right] \\
R_{e}=A\left[\left(16+B D_{g r}^{3}\right)^{0.5}-4\right]
\end{gathered}
$$

where $D_{g r}$ is the dimensionless particle size calculated as $D_{g r}=\left[\frac{g(s-1)}{\vartheta^{2}}\right]^{\frac{1}{3}} d$.

The only differences among these equations are given by the coefficients $(A$ and $B)$; the values of these coefficients are 2.5 and 0.16 for Zanke [3], 2.59 and 0.156 for Soulsby [12], and 2.0 and 0.222 for Julien [10]. The main reason for different coefficient values is due to the different data sets used while doing their empirical calibrations.

Rijn [5] proposed an equation with some complexity, i.e., an equation containing trigonometric terms that depend on the non-dimensional number. He adopted the Stokes equation for $d<0.01 \mathrm{~cm}$ :

$$
\begin{array}{cc}
\omega_{s}=\frac{1}{18} \frac{g(s-1) d^{2}}{\vartheta} & \text { For } \quad d<0.01 \mathrm{~cm} \\
\omega_{s}=1.1 \sqrt{[(s-1) g d]} & \text { For } \quad d>0.1 \mathrm{~cm} \\
\omega_{s}=\frac{10 \vartheta}{d}\left[\sqrt{\left(1+0.01 d^{3}\right)}\right] & \text { For } \quad d=0.01-0.1 \mathrm{~cm}
\end{array}
$$

Zhu and Cheng [6] proposed a simple equation with the different diameter range:

$$
\omega_{s}=\frac{\vartheta\left[-24(\cos \alpha)^{3}+\left(576(\cos \alpha)^{6}+\left(18(\cos \alpha)^{3}+3.6(\sin \alpha)^{2}\right) D_{g r}^{3}\right)^{0.5}\right]}{d\left(9(\cos \alpha)^{3}+1.8(\sin \alpha)^{2}\right)}
$$

where $D_{g r}$ is a non-dimensional particle parameter calculated as:

$$
D_{g r}=\left[\frac{g(s-1)}{\vartheta^{2}}\right]^{\frac{1}{3}} d
$$

For, $D_{g r} \leq 1 ; \alpha=0$ and $D_{g r} \leq 1 ; \alpha=\frac{\pi}{\left[2+2.5\left(\log D_{g r}\right)^{-3}\right]}$. 
Cheng [7] proposed a simple equation to predict the settling velocity of natural sediment particles.

$$
\omega_{s}=\frac{\vartheta}{d}\left(\sqrt{25+1.2 D_{g^{r}}^{2}}-5\right)^{1.5}
$$

Cheng [7] did not directly consider the shape factor and roundness value in this equation and assumed the standard shape factor for natural sediments as 0.7.

Wu and Wang [15] suggested a simple equation for calculating the settling velocity of sediment particles. In this equation, the particle shape factor considers explicitly:

$$
\omega_{s}=\frac{M \vartheta}{N d}\left[\sqrt{\left(\frac{4 N}{3 M^{2}} D_{g r}^{3}\right)^{\frac{1}{n}}+\frac{1}{4}}-\frac{1}{2}\right]^{n}
$$

where $M, N$, and $n$ are calibration coefficients calculated as $M=53.5 e^{-0.65 S_{f}}, N=$ $5.65 e^{-2.5 S_{f}}$, and $n=0.7+0.9 S_{f} . S_{f}$ is the safe factor.

Jimenez and Madsen [8] developed an equation to predict the settling velocity. They derived this equation from the previous development of Dietrich [18], and it calculates the fall velocity of sediment particles for a given particle shape factor, roundness parameter, and diameter:

$$
\omega_{s}=\frac{\sqrt{(S-1) g d}}{A+\frac{B}{S_{*}}}
$$

where $A, B$, depend on the Corey shape factor (CSF) and particle roundness $(P)$. For natural sediment particles $(C S F=0.7, \mathrm{P}=3.5)$, the proposed standard values of $A, B$, are 0.954 and 5.12 , respectively. $S_{*}$ is the dimensionless sediment parameter calculated as:

$$
S_{*}=\frac{d}{4 \vartheta} \sqrt{(s-1) g d}
$$

Camenen [16] developed an equation to predict the settling velocity. Explicitly, the particle size, shape factor, and roundness effects have been included in this equation:

$$
\omega_{s}=\frac{\vartheta}{d}\left[\sqrt{\frac{1}{4}\left(\frac{A}{B}\right)^{\frac{2}{n}}+\left(\frac{4}{3} \frac{D_{g r}^{3}}{B}\right)^{\frac{1}{n}}}-\frac{1}{2}\left(\frac{A}{B}\right)^{\frac{1}{n}}\right]^{n}
$$

$A, B$, and $n$ are the calibration coefficients, functions of shape factor $\left(S_{f}\right)$, and roundness $(P)$ :

$$
\begin{gathered}
A=a_{1}+a_{2}\left[1-\sin \left(\frac{\pi}{2} S_{f}\right)\right]^{a_{3}} \\
B=b_{1}+b_{2}\left[1-\sin \left(\frac{\pi}{2} S_{f}\right)\right]^{b_{3}} \\
n=n_{1}\left(\sin \frac{\pi}{2} S_{f}\right)^{n_{2}}
\end{gathered}
$$

At particle roundness $(P=3.5): a_{1}=24, a_{2}=100, a_{3}=2.31 ; b_{1}=0.94, b_{2}=20, b_{3}=2.975$, and $n_{1}=1.62 ; n_{2}=0.47$.

\section{Data Description}

A large number of field and laboratory experimental datasets for settling the velocity of natural sediments were collected from the literature. There were 226 field and laboratory data taken from previous investigations. All the data sets are summarized in Table 1. These data sets were categorized into two groups, viz.: (i) in the first category, the shape factor has not been specified directly, and particle is represented as natural sediment grains 
(shape factor assumed as 0.7 ); and (ii) the second category data set contains the shape factor directly.

The first group corresponds to the fall velocity of natural sediment particles with an assumption of shape factor of 0.7 taken from Engelund and Hansen [19], Hallermeier [4], and Cheng [7]. Engelund and Hansen [19] collected a settling velocity data set from Hallermeier [4]. In this data, particle size was classified as sieve diameter $\left(d_{s}\right)$; it was converted into nominal diameter $\left(d_{N}\right)$ by the thumb rule $\frac{d_{s}}{d_{N}}=0.9$ [20]. Because the kinematic viscosity $\vartheta$ and specific gravity s were not given, they were assumed to correspond to fresh water at the given temperature [21]. Previously, research has shown the importance of settling velocity and suspended sediments on river health management [22-32].

Table 1. Data description and properties.

\begin{tabular}{|c|c|c|c|c|c|c|}
\hline Parameters & No. of Data & $d(\mathrm{~mm})$ & $S(-)$ & $\operatorname{CSF}(-)$ & $\vartheta\left(\frac{c m^{2}}{s}\right)$ & $\omega_{s}\left(\frac{\mathrm{cm}}{\mathrm{s}}\right)$ \\
\hline Briggs [24] & 110 & $0.09-0.5$ & $3.97-5.07$ & $0.049-0.881$ & 0.01 & $0.9-9.5$ \\
\hline Engelund and Hansen [19] & 21 & $0.01-2.0$ & 2.65 & 0.7 & $0.01-0.0131$ & $0.5-17.0$ \\
\hline Hallermeier [4] & 21 & $0.09-1.3$ & 2.65 & 0.7 & $0.0084-0.0114$ & $0.54-14$ \\
\hline Raudkivi [20] & 36 & $0.2-2.0$ & 2.65 & $0.5-0.9$ & $0.009-0.0131$ & $1.68-24.0$ \\
\hline Cheng [7] & 38 & $0.06-4.5$ & 2.65 & 0.7 & $0.0114-0.0141$ & $0.235-28.1$ \\
\hline
\end{tabular}

The second group data sets correspond to the fall velocity of sediment particles, including the shape factor. Briggs [24] consists of experimental data on heavy minerals of specific gravity of about 2.65, and the shape factor ranges from 0.2 to 0.9 . The data sets of settling velocities were noted by Raudkivi [20]. The data consisted of the fall velocity of sediment particles represented by their shape factor and nominal diameter.

\section{Results and Discussions}

\subsection{Performances of Existing Equations}

In this present study, a total of fourteen (eleven without $S_{f}$; three with $S_{f}$ ) equations proposed by earlier investigators $[2,3,5-10,12,15,16]$ were checked with 226 field and laboratory experimental data sets $[4,7,19,20,24]$. The accuracy and reliability of these equations were analysed both graphically and statistically. In Figures $1 \mathrm{a}-\mathrm{k}$ and $2 \mathrm{a}-\mathrm{c}$, values on $X$-axis and $Y$-axis represent the observed and predicted data sets of the settling velocity of particles, respectively. The data set has been divided into two groups: one is without the shape factor (assumed as a natural particle, $S_{f}=0.7$ ); the second is with the shape factor (shape factor considered explicitly). The first group consists of data sets of Engelund and Hansen [19], Hallermeier [4], and Cheng [7]. The second group consists of the data sets of Briggs [24] and Raudkivi [20].

Figure $1 \mathrm{i}, \mathrm{k}$ are the graphical representation of the observed and predicted data by the equations of Jimenez and Madsen [8] and Camenen [16] without the shape factor. Results show that the equations of both Jimenez and Madsen [8] and Camenen [16] performed well and produced nearly the same results for fine sediments (lower settling velocity); in the case of coarse sediments (higher settling velocity), these equations performed slightly under prediction and over prediction, respectively. There is a limitation for Jimenez and Madsen's [8] equation, as it was developed for a certain diameter range $(0.63 \mathrm{~mm}-1 \mathrm{~mm})$.

The equation of Cheng [7] also showed good agreement with the observed data without the shape factor (natural sediment particles, i.e., $S_{f}$ assumed as 0.7 ), and a slight under prediction is observed through scatter plot $1(\mathrm{~g})$. Zhang's [9] expression was over predicted for lower settling velocity between $2-9 \mathrm{~cm} / \mathrm{s}$ and further observed good agreement with measured settling velocity data, shown in Figure 1d. The agreement between observed and predicted data of Zanke [3], Soulsby [12], and Julien [10] expressions are shown in Figure $1 b, f, h$, respectively. Due to similarities between equations, these three expressions 
show analogous trends in their scatter plots, and Julien's [10] equation showed lower accuracy graphically and statistically. Rijn [5] gave over prediction with moderate performance as shown in Figure 1c. Rijn [5] divided datasets into three sediment diameter ranges $(d<0.01 \mathrm{~cm}, d>0.1 \mathrm{~cm}$, and $d=0.01-0.1 \mathrm{~cm})$ and most of the collected datasets belonged to $d>0.01 \mathrm{~cm}$, which may be the reason for over prediction with moderate performance. Figures $1 \mathrm{j}$ and $2 \mathrm{~b}$ show the agreement between observed and predicted settling velocity by the equation of Wu and Wang [15], with and without the shape factor, respectively. Wu and Wang [15] included the importance of the shape factor and excluded the particle roundness factor. This was done so that it could be used only for data that excludes the roundness factor; if not, an error in the particle's settling velocity calculations could occur.

Most of the data showed incredibly good agreement graphically and statistically because of a simple equation that explicitly included the effect of the shape factor. Camenen's [16] expression with the inclusion of the shape factor produced a low agreement with the observed data, which can be seen in Figure 2c. It would have been shown to be in good agreement when the shape factor is considered; however, the results showed low agreement because of the complex equation and insufficient data of all parameters. The expression of Jimenez and Madsen [8] with the shape factor showed poor agreement compared with the above mentioned equations for these data sets. The equations of Ruby [2] and Zhu and Cheng [6] showed extremely poor agreement with the observed data with under and over prediction, respectively.

In computing the settling velocity of sediment particles, the authors observed that the equation proposed by $\mathrm{Wu}$ and Wang [15] (with and without shape factor) illustrates better agreement with the predicted and observed data than the others. However, the reason for the poor performance of Jimenez and Madsen's [8] and Camenen's [16] equations with shape factors may be due to the complexity of their equations and inadequate data sets.
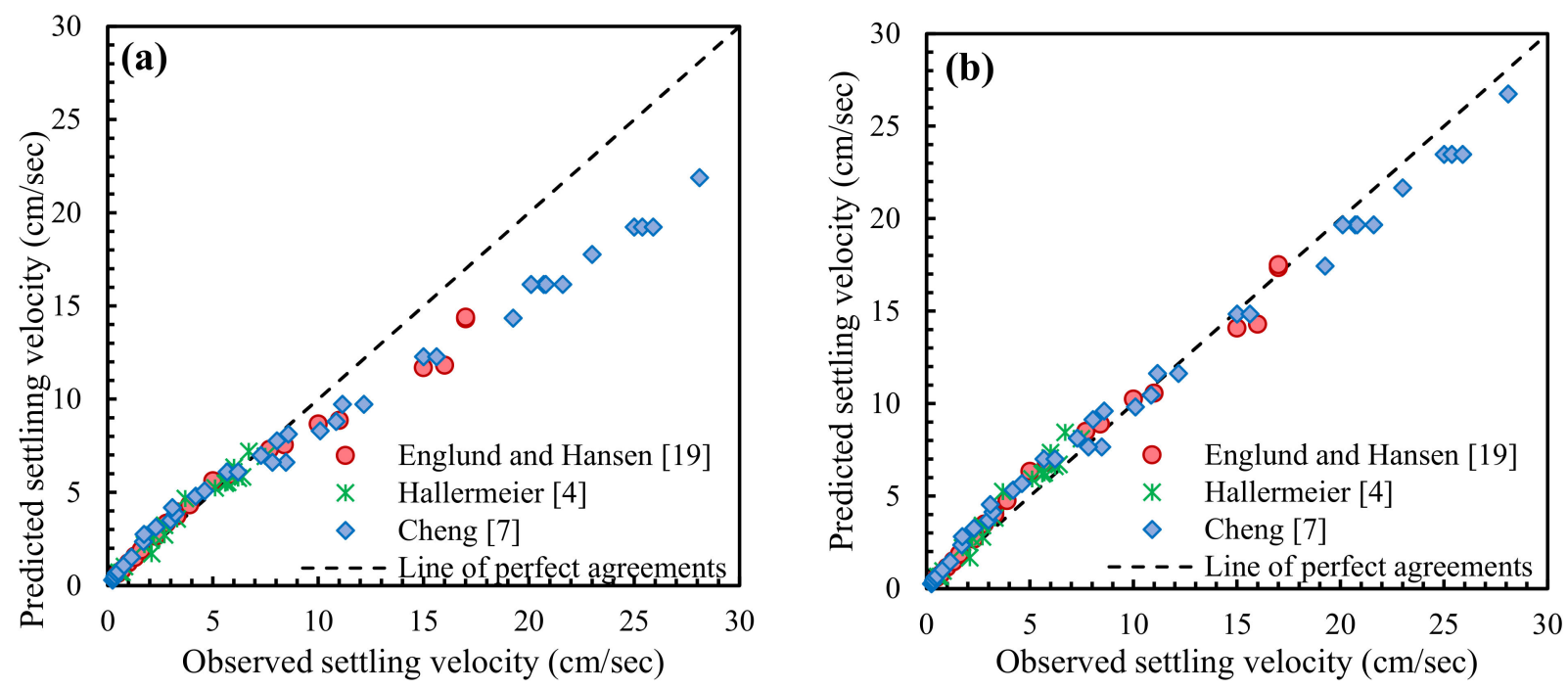

Figure 1. Cont. 

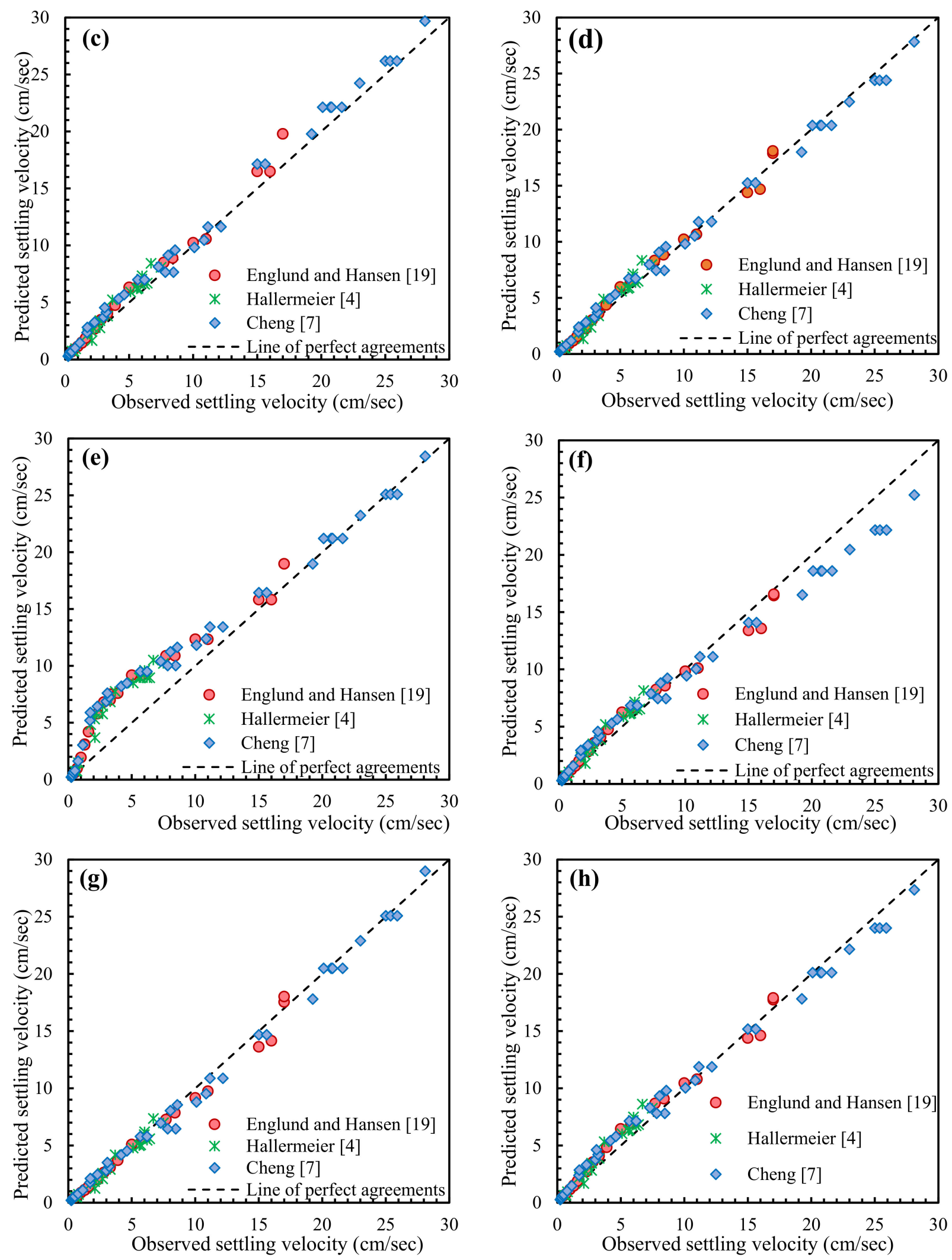

Figure 1. Cont. 

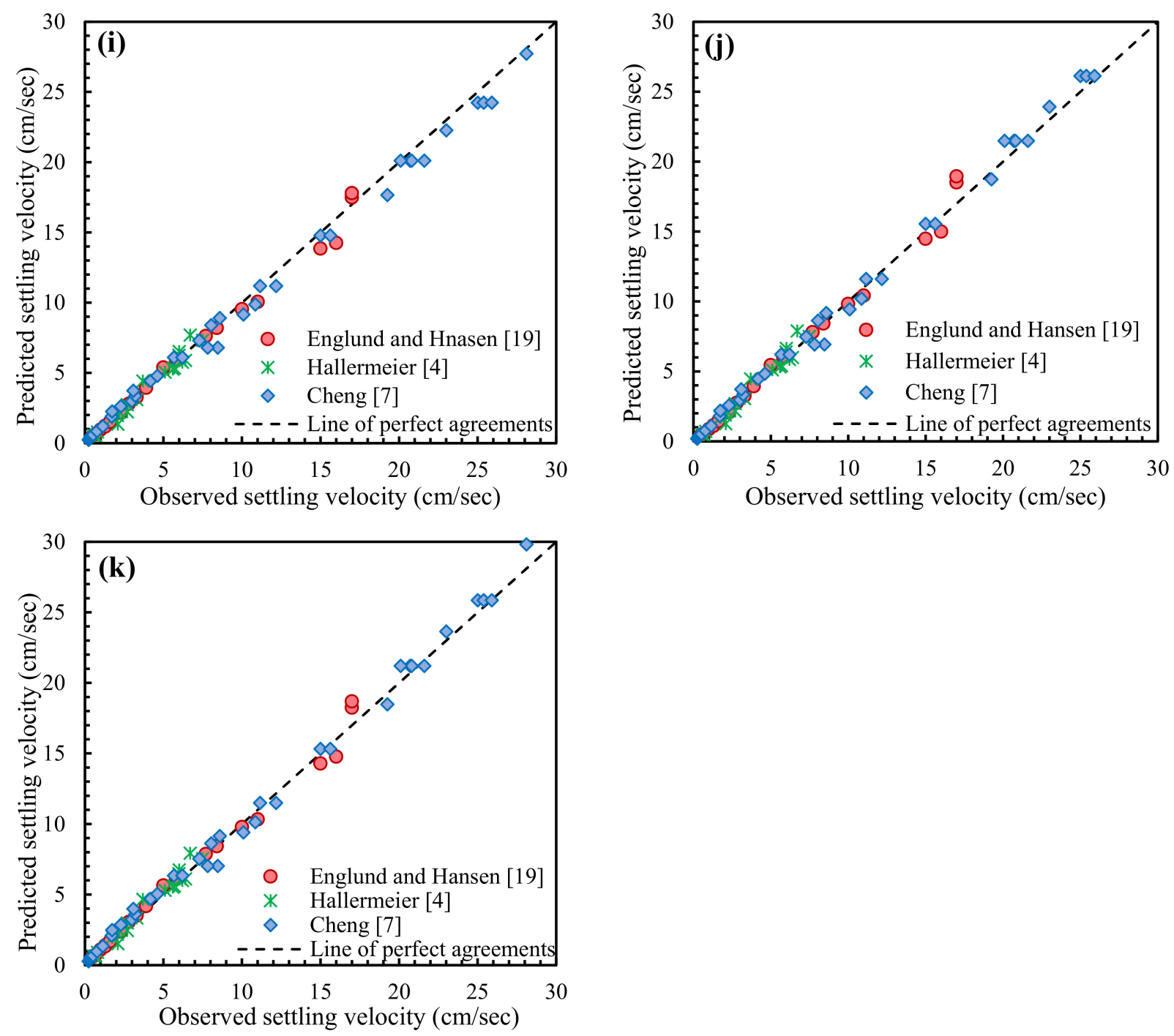

Figure 1. (a-j) Observed versus predicted settling velocity without shape factor using: (a) Ruby [2]; (b) Zanke [3]; (c) Rijn [5]; (d) Zhang [9]; (e) Zhu and Cheng [6]; (f) Julien [10]; (g) Cheng [7]; (h) Soulsby [12]; (i) Jimenez and Madsen [8]; (j) Wu and Wang [15]; and (k) Camenen [16].

\subsection{Statistical Performance Analysis of Equations}

A statistical analysis was also done to check the accuracy of these equations. Five statistical indices were taken to enhance the agreement between the predicted and observed settling velocity of sediment particles with and without shape factor. If $M$ is the measured (or observed) value and $P$ is the corresponding predicted (or computed) value, the various performance indices are defined as shown in Equation (12). The co-efficient of determination $\left(R^{2}\right)$ explains the fraction of total variance in observed data sets, and it ranges from 0 to 1 :

$$
R^{2}=\frac{\sum_{i=1}^{n}\left(M_{i}-\bar{M}\right)\left(P_{i}-\bar{P}\right)}{\sqrt{\sum_{i=1}^{n}\left(M_{i}-\bar{M}\right)^{2}} \sqrt{\sum_{i=1}^{n}\left(P_{i}-\bar{P}\right)^{2}}}
$$

where, $M_{i}=$ Observed data, $P_{i}=$ Predicted data, $\bar{M}=$ mean of observed data, and $\bar{P}=$ mean of predicted data. 

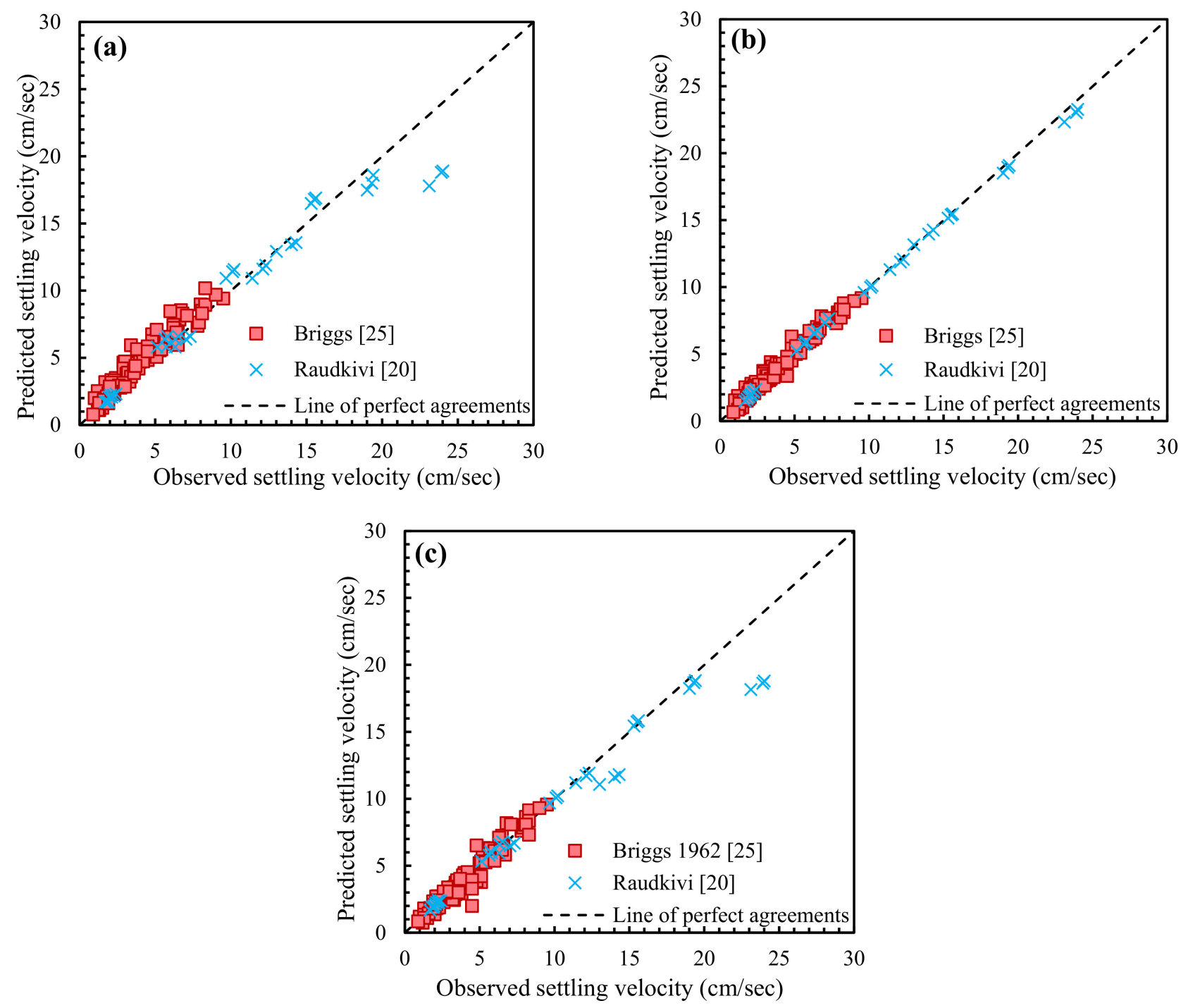

Figure 2. (a-c) Observed versus predicted settling velocity with shape factor using: (a) Jimenez and Madsen [8]; (b) Wu and Wang [15]; and (c) Camenen [16].

Nash-Sutcliffe efficiency (NSE) is the most extensively used index. It represents the absolute difference between measured and predicted data, which is then normalized with the measured variance. The range exists between $-\infty$ and 1 , with 1 representing the perfect fit.

$$
E=1-\frac{\sum_{i=1}^{n}\left(M_{i}-P_{i}\right)^{2}}{\sum_{i=1}^{n}\left(M_{i}-\bar{M}\right)^{2}}
$$

Kling-Gupta efficiency (KGE)

$$
E=1-E D
$$

$E D$ is calculated as,

$$
E D=\sqrt{(r-1)^{2}+\left(\frac{\sigma_{p}}{\sigma_{m}}-1\right)^{2}+\left(\frac{\mu_{p}}{\mu_{m}}-1\right)^{2}}
$$


where; $E D=$ Euclidian distance from the ideal point, $r=$ linear correlation coefficient between predicted and observed data, $\sigma_{p}, \sigma_{m}=$ standard deviation of predicted and observed data, respectively, and $\mu_{p}, \mu_{m}=$ mean of predicted and observed data, respectively.

Percent bias (PBIAS) represents the average deviation in percentage of the predicted data from the observed data.

$$
\text { PBIAS }=\frac{\sum_{i=1}^{n}\left(M_{i}-P_{i}\right)}{\sum_{i=1}^{n} M_{i}} \times 100
$$

Mean Absolute Error $(M A E)$ :

$$
M A E=\frac{1}{n} \sum_{i=1}^{n}\left|\left(M_{i}-P_{i}\right)\right|
$$

In Equations (21)-(26), $n$ is the number of data sets, i.e., 226. Values of $R^{2}, N S E, K G E$, PBIAS, and MAE for different equations are listed in Table 2. The $R^{2}$, NSE, and KGE of Equation (14), i.e., proposed by Wu and Wang [15], are highest, and PBIAS and MAE are lowest among all other equations. Statistical performances indicate that the expression of $\mathrm{Wu}$ and Wang [15] predicts the better settling velocity of sediment particles than all other equations. This was observed graphically and statistically. The expressions proposed by Camenen [16] and Jimenez and Madsen [8] without the shape factor provided the second highest agreements between observed and predicted data, as can be seen in Table 2 and Figure 1.

\begin{tabular}{|c|c|c|c|c|c|}
\hline Researchers & $N S E$ & $K G E$ & PBIAS & $M A E$ & $R^{2}$ \\
\hline Wu and Wang [15] with $S_{f}$ & 0.9937 & 0.976 & -1.06 & 0.2691 & 0.9942 \\
\hline Wu and Wang [15] without $S_{f}$ & 0.9931 & 0.9616 & -1.463 & 0.4107 & 0.9948 \\
\hline Camenen [16] without $S_{f}$ & 0.9936 & 0.9733 & -2.3895 & 0.4376 & 0.9944 \\
\hline Jimenez and Madsen [8] without $S_{f}$ & 0.9929 & 0.9512 & 2.6308 & 0.4164 & 0.9952 \\
\hline Cheng [7] without $S_{f}$ & 0.9924 & 0.96 & 3.8275 & 0.4342 & 0.9941 \\
\hline Zhang [9] without $S_{f}$ & 0.9925 & 0.964 & -1.7206 & 0.4835 & 0.9937 \\
\hline Zanke [3] without $S_{f}$ & 0.9847 & 0.9143 & -2.4174 & 0.7276 & 0.9914 \\
\hline Soulsby [12] without $S_{f}$ & 0.9861 & 0.9241 & -4.5574 & 0.7057 & 0.9915 \\
\hline Rijn [5] without $S_{f}$ & 0.9824 & 0.8998 & -9.1874 & 0.7705 & 0.9933 \\
\hline Camenen [16] with $S_{f}$ & 0.9581 & 0.8958 & 3.4168 & 0.5018 & 0.9661 \\
\hline Julien [10] without $S_{f}$ & 0.9714 & 0.8582 & 1.0309 & 0.9229 & 0.9901 \\
\hline Jimenez and Madsen [8] with $S_{f}$ & 0.9234 & 0.8648 & -6.1132 & 0.8406 & 0.9354 \\
\hline Ruby [2] without $S_{f}$ & 0.9069 & 0.7104 & 12.4768 & 1.3657 & 0.989 \\
\hline Zhu and Cheng [6] without $S_{f}$ & 0.8707 & 0.7057 & -28.4017 & 2.1954 & 0.9599 \\
\hline
\end{tabular}

Table 2. Statistical values.

\section{Conclusions}

The present study describes the settling velocity phenomenon and deals with the methods for its estimation. A total of fourteen equations (eleven without $S_{f}$; three with $S_{f}$ ) were used for verifying the accuracy and performance of particle settling velocity. The authors graphically observed that the relationship proposed by Wu and Wang [15], with and without the shape factor, provides superior agreements, as is shown in Figures $1 \mathrm{j}$ and $2 \mathrm{~b}$. Statistically, the relationships proposed by $\mathrm{Wu}$ and Wang [15], with and without the shape factor, and Camenen [16], Jimenez and Madsen [8], and Cheng [7], without the shape factor, provide approximately similar values among all. However, Wu and Wang [15] show slightly higher 
values than the other equations, as shown in Table 2. Graphically and statistically, it was observed that the expressions of Zanke [3], Soulsby [12], and Julien [10] show the same pattern with medium performance. The low performance of Jimenez and Madsen's [8] and Camenen's [16] equations may be strictly due to particular datasets. There may be a scope for checking the accuracy of the above equations with broad datasets, including particle shape factor and roundness factor.

Finally, it was determined by the authors after graphical and statistical investigations that the expression proposed by Wu and Wang [15] predicts the settling velocity of sediment particles both with and without the shape factor cases, showing the least errors among all equations. Hence, the present study highlights that Wu and Wang's [15] equation predicts the accurate value of settling velocity of a particle.

Author Contributions: M.P. collected experimental data and prepared a rough draft of the manuscript; M.P. and M.S.S. analysed the data and applied methodology; and M.P. and A.K.S. completed the manuscript writing-review and editing. Funding acquisition, A.K.S. All authors have read and agreed to the published version of the manuscript.

Funding: This research was funded by Manipal Academy of Higher Education, Manipal, Udupi, Karnataka, India.

Institutional Review Board Statement: Not applicable.

Informed Consent Statement: Not applicable.

Data Availability Statement: Not applicable.

Acknowledgments: The authors are thankful to the late E. Venkata Rathnam for choosing a research topic and providing excellent guidance and painstaking efforts throughout the present research work.

Conflicts of Interest: The authors declare no conflict of interest.

\section{References}

1. Gibbs, R.J.; Matthews, M.D.; Link, D.A. The relationship between sphere size and settling velocity. J. Sediment. Res. 1971, 41, 7-18.

2. Ruby, W. Settling velocities of gravel, sand and silt particles. Am. J. Sci. 1933, 25, 325-338. [CrossRef]

3. Zanke, U. Berechnung der Sinkgeschwindigkeiten von Sedimenten; Heft 46, Seite 243; Franzius-Institut für Wasserbau und Küsteningenieurwesen: Hannover, Germany, 1977.

4. Hallermeier, R.J. Terminal settling velocity of commonly occurring sand grains. Sedimentology 1981, 28, 859-865. [CrossRef]

5. Rijn, L.C.V. Sediment transport, part II: Suspended load transport. J. Hydraul. Eng. 1984, 110, 1613-1641. [CrossRef]

6. Zhu, L.J.; Cheng, N.S. Settlement of Sediment Particles; Resp. Rep., Dept of River and Harbor Eng. Nanjing Hydr. Res. Inst.: Nanjing, China, 1993. (In Chinese)

7. Cheng, N.S. Simplified Settling Velocity Formula for Sediment Particle. J. Hydraul. Eng. 1997, 123, 149-152. [CrossRef]

8. Jiménez, J.A.; Madsen, O.S. A simple formula to estimate settling velocity of natural sediments. J. Waterw. Port Coast. Ocean Eng. 2003, 129, 70-78. [CrossRef]

9. Zhang, R.J. River Dynamics; Industry Press: Beijing, China, 1961. (In Chinese)

10. Julien, P.Y. Erosion and Sedimentation; Cambridge University Press: Cambridge, UK, 2010.

11. Pandey, M.; Sharma, P.K.; Ahmad, Z.; Singh, U.K.; Karna, N. Three-dimensional velocity measurements around bridge piers in gravel bed. Mar. Georesour. Geotechnol. 2018, 36, 663-676. [CrossRef]

12. Soulsby, R. Dynamics of Marine Sands: A Manual for Practical Applications; Thomas Telford: Telford, UK, 1997.

13. Pourshahbaz, H.; Abbasi, S.; Pandey, M.; Pu, J.H.; Taghvaei, P.; Tofangdar, N. Morphology and hydrodynamics numerical simulation around groynes. ISH J. Hydraul. Eng. 2020, 1-9. [CrossRef]

14. Ahrens, J.P. A fall-velocity equation. J. Waterw. Port Coast. Ocean Eng. 2000, 126, 99-102. [CrossRef]

15. Wu, W.; Wang, S.S. Formulas for sediment porosity and settling velocity. J. Hydraul. Eng. 2006, 132, 858-862. [CrossRef]

16. Camenen, B. Simple and general formula for the settling velocity of particles. J. Hydraul. Eng. 2007, 133, 229-233. [CrossRef]

17. Stokes, G.G. On the effect of the internal friction of fluids on the motion of pendulums. Trans. Camb. Phil. Soc. 1851, 9, 8-106.

18. Dietrich, W.E. Settling velocity of natural particles. Water Resour. Res. 1982, 18, 1615-1626. [CrossRef]

19. Engelund, F.; Hansen, E. A Monograph on Sediment Transport in Alluvial Streams; Technical University of Denmark: Copenhagen, Denmark, 1967.

20. Raudkivi, A.J. Loose Boundary Hydraulics, 3rd ed.; Technical report; Pergamon Press: Oxford, UK, 1990.

21. Zegzhda, A.P. Settlement of Sand Gravel Particles in Still Water; Izv. NIIG, 12; Moscow, Russia, 1934. (In Russian)

22. Arkangel'skii, B.V. Experimental Study of Accuracy of Hydraulic Coarseness Scale of Particles; Isv. NHG, 15; 1935.

23. Sarkisyan, A.A. Deposition of Sediment in a Turbulent Stream; Izd. AN SSSR: Moscow, Russia, 1958. (In Russian) 
24. Briggs, L.I.; McCulloch, D.S.; Moser, F. The hydraulic shape of sand particles. J. Sediment. Res. 1962, 32, $645-656$.

25. Amit, K.; Sharma, M.P.; Rai, S.P. A novel approach for river health assessment of Chambal using fuzzy modeling, India. Desalination Water Treat. 2017, 58, 72-79.

26. Pandey, M.; Lam, W.H.; Cui, Y.; Khan, M.A.; Singh, U.K.; Ahmad, Z. Scour around Spur Dike in Sand-Gravel Mixture Bed. Water 2019, 11, 1417. [CrossRef]

27. Kumar, A.; Cabral-Pinto, M.; Kumar, M.; Dinis, P.A. Estimation of risk to the eco-environment and human health of using heavy metals in the Uttarakhand Himalaya, India. Appl. Sci. 2020, 10, 7078. [CrossRef]

28. Singh, R.K.; Pandey, M.; Pu, J.H.; Pasupuleti, S.; Villuri, V.G.K. Experimental study of clear-water contraction scour. Water Supply 2020, 20, 943-952. [CrossRef]

29. Kumar, A.; Mishra, S.; Taxak, A.K.; Pandey, R.; Yu, Z.G. Nature rejuvenation: Long-term (1989-2016) vs short-term memory approach based appraisal of water quality of the upper part of Ganga River, India. Environ. Technol. Innov. 2020, $20,101164$. [CrossRef] [PubMed]

30. Singh, U.K.; Ahmad, Z.; Kumar, A.; Pandey, M. Incipient motion for gravel particles in cohesionless sediment mixtures. Iran. J. Sci. Technol. Trans. Civ. Eng. 2019, 43, 253-262. [CrossRef]

31. Mishra, S.; Kumar, A.; Shukla, P. Estimation of heavy metal contamination in the Hindon River, India: An environmetric approach. Appl. Water Sci. 2021, 11, 2. [CrossRef]

32. Singh, P.; Kumar, A.; Mishra, S. Performance evaluation of conservation plan for freshwater lakes in India through a scoring methodology. Environ. Dev. Sustain. 2021, 23, 3787-3810. [CrossRef] 